Proceedings of the 10th International Ruminant Reproduction Symposium (IRRS 2018); Foz do Iguaçu, PR, Brazil, September 16th to 20th, 2018.

\title{
Evolution of knowledge on ovarian physiology and its contribution to the widespread application of reproductive biotechnologies in South American cattle
}

\author{
Reuben J. Mapletoft ${ }^{1, *}$, Gabriel A. Bó ${ }^{2}$, Pietro S. Baruselli ${ }^{3}$, Alejo Menchaca ${ }^{4}$, Roberto Sartori ${ }^{5}$ \\ ${ }^{1}$ WCVM, University of Saskatchewan, Saskatoon, SK, Canada. \\ ${ }^{2}$ Instituto de Reproducción Animal Córdoba (IRAC) and Universidad Nacional de Villa Maria, Cordoba, Argentina. \\ ${ }^{3}$ Department of Animal Reproduction, University of São Paulo, São Paulo, SP, Brazil \\ ${ }^{4}$ Instituto de Reproducción Animal Uruguay Fundación IRAUy, Montevideo, Uruguay. \\ ${ }^{5}$ Department of Animal Science, University of São Paulo, Piracicaba, SP, Brazil.
}

\begin{abstract}
As our understanding of ovarian function in cattle has improved, our ability to control it has also increased. Luteal function in cattle has been studied in detail, and prostaglandin F2 $\alpha$ has been used for several years for the elective induction of luteal regression. More recently, follicle wave dynamics has been studied and protocols designed to induce follicular wave emergence and ovulation have reduced, and even eliminated, the need for estrus detection. The addition of progestin-releasing devices, estradiol, $\mathrm{GnRH}$ and equine chorionic gonadotropin (eCG) have provided opportunities for fixed-time AI (FTAI) and possibilities for increased pregnancy rates. In embryo transfer programs, these same treatments have eliminated the need for estrus detection, permitting fixed-time embryo transfer and the initiation of superstimulatory treatments without regard to day of the estrous cycle. Collectively, new treatment protocols have facilitated the application of assisted reproductive technologies, and this is especially true in South America. Over the last 20 years, the use of AI in South America has increased, due largely to the use of FTAI. There has been more than a 10 -fold increase in the use of FTAI in Brazil with more than 11 million treatments in 2016, representing $85 \%$ of all AI. Similar trends are occurring in Argentina and Uruguay. Production of in vivo-derived (IVD) embryos has remained relatively stable over the years, but in vitro embryo production (IVP) has increased dramatically over the past 10 to 15 years, especially in Brazil where more than 300,000 IVP embryos were produced in 2010. World-wide, more than 666,000 bovine IVP embryos were produced in 2016, of which more than $57 \%$ were produced in South America. The use of assisted reproductive technologies has facilitated the dissemination of improved genetics and increased reproductive performance; other South American countries are now following suit.
\end{abstract}

Keywords: AI, embryo transfer, estrus synchronization, follicular wave, superovulation.

\section{Introduction}

Increasing knowledge of ovarian physiology in cattle over the past 50 years has provided approaches for the manipulation of ovarian function. Protocols designed to control both luteal and follicular function have improved estrus synchronization and permitted fixed-time AI (FTAI) and fixed-time embryo transfer (FTET), and the initiation of superstimulatory treatments at a self-appointed time. Bovine practitioners around the world are now using these reproductive technologies, and this is especially the case in South America. This review will briefly describe improvements in our understanding of ovarian physiology in cattle and discuss how this has affected the application of assisted reproductive biotechnologies in South America, with special emphasis on Brazil, Argentina and Uruguay where much of the research and practical application is taking place.

\section{A brief review of recent knowledge on ovarian physiology in cattle}

Ovarian follicles in cattle grow in a wave-like fashion. A follicular wave consists of the synchronous emergence of a group of antral follicles 4 to $5 \mathrm{~mm}$ in diameter followed in 2 or 3 days by the selection of one follicle to become dominant, while subordinates become atretic (Ginther et al., 1989a). Estrous cycles in cattle are composed of either 2 or 3 follicular waves (Ginther et al., 1989b), although 4-wave cycles have been reported in B. indicus breeds (Bó et al., 2003). In both 2- and 3-wave cycles, emergence of the first follicular wave occurs on the day of ovulation (Day 0). Because of the presence of the mid-cycle CL, the dominant follicle of the first wave regresses, and a second wave emerges on Days 9 or 10 in 2-wave cycles, and Days 8 or 9 in 3-wave cycles, with the third wave emerging on Days 15 or 16. Follicular waves occur in heifers before puberty and in postpartum cows, before the first ovulation (reviewed in Adams, 1999).

Recruitment of follicular waves and selection of the dominant follicle are based on differential responsiveness of antral follicles to FSH and $\mathrm{LH}$ (reviewed in Adams, 1999). Surges in circulating FSH are followed in 1 to 2 days by the appearance of a group of follicles that are 4 to $5 \mathrm{~mm}$ in diameter. FSH is then suppressed by estradiol and inhibin produced by follicles in the wave (especially the future dominant follicle), leading to the selection of a dominant follicle approximately 3 days after wave emergence. The dominant follicle acquires more LH receptors on its granulosa cells than its subordinates and is able to shift its gonadotropin dependence to LH during the period of low FSH; it continues to grow while subordinates 
requiring FSH regress (Ginther et al., 2001). Suppression of LH by progesterone from the CL causes the dominant follicle of the first wave (and of the second wave in 3wave cycles) to eventually cease its metabolic functions and regress, which leads to an FSH surge and emergence of a new follicular wave (Adams, 1999). Luteal regression results in increased $\mathrm{LH}$ pulse frequency, increased growth of the dominant follicle, elevated estradiol concentrations, an LH surge and ovulation.

The number of follicular waves in cattle depends on the duration of follicular dominance in the first wave; it is 3 days longer and the onset of regression occurs later during 2-wave cycles than 3-wave cycles. However, the onset of luteolysis occurs earlier in 2wave cycles resulting in an interovulatory interval of 20 days, as compared to 23 days in 3-wave cycles (Adams, 1999; Sartori et al., 2004). The reason for difference in the duration of follicular dominance in the first wave between wave types is unknown. The dominant follicle present at the time of luteolysis becomes the ovulatory follicle, and emergence of the next wave is delayed until the ensuing ovulation (Kastelic and Ginther, 1991).

Follicular wave dynamics as described has been limited to follickes $4 \mathrm{~mm}$ because of the resolution of early ultrasound equipment. However, newer equipment has permitted the identification of the future dominant follicle at a diameter of $1 \mathrm{~mm}$, suggesting that 1 to $3 \mathrm{~mm}$ follicles also develop in a wave-like manner (Fig. 1). Adams et al. (2008) pointed out that at a microscopic level, there is no morphologic distinction between follicles that are 1 to $3 \mathrm{~mm}$ and those that are more than $3 \mathrm{~mm}$, and that at a cellular level, both size categories not only express FSH receptors but have a similar level of expression on a per granulosa cell basis (reviewed in Bao and Garvarick, 1998). They also provide evidence that these small antral follicles respond to transient elevations in circulating FSH and that their growth progresses over a period encompassing the entire FSH surge. Thus, 1 to 3 $\mathrm{mm}$ follicles may be an important component of the wave. This has implications for the optimization of superstimulation for both in vivo and in vitro embryo production in cattle (Garcia Guerra et al., 2015).

There are several differences in reproductive function between $B$. indicus and B. taurus breeds of cattle and these must be considered when designing assisted reproductive programs. Nutrition, post-partum anestrus and age of onset of puberty are especially important in B. indicus cattle. They also have a shorter estrus period, often expressed during the night, and although follicular dominance is similar, maximum diameters of the dominant follicle and CL are smaller (Bó et al., 2003), as are dominant follicle diameters at the time of selection and ovulation (Sartori et al., 2001; Sartorelli et al., 2005; Gimenes et al., 2008). In addition, $B$. indicus breeds tend to be more sensitive to steroid hormones which must be considered in designing estrus synchronization programs (Bó et al., 2003). However, $B$. indicus breeds also have greater antral follicle counts (Batista et al., 2014; Sartori et al., 2016a) which has important implications for superstimulation and ovum pick-up and in vitro fertilization (OPU/IVF).

\section{Synchronization of estrus for artificial insemination or embryo transfer}

\section{Prostaglandin F2a}

Prostaglandin F2 $\alpha$ (PGF) has become the most common treatment for elective induction of luteal regression and synchronization of estrus in cattle (reviewed in Odde, 1990). However, cattle must be cycling and PGF will not induce luteolysis during the first 5 days of the cycle (Seguin, 1987). In addition, the onset of estrus may occur over several days; treatment when the dominant follicle is near mature will result in ovulation in 2 or 3 days, whereas treatment when it is no longer viable will result in ovulation of the dominant follicle of the next wave, 4 to 5 days later (Kastelic et al., 1990). In a two-dose PGF synchronization scheme, an interval of 10 or 11 days has been recommended to ensure that all cattle have a PGF-responsive CL at the time of the second treatment. Although an interval of 11 days between PGF treatments has been found to be acceptable for heifers (Selk et al., 1988), higher conception rates have been reported in lactating dairy cows with a 14-day interval (Folman et al., 1990). Most other methods of estrus synchronization utilize PGF to regress an existing or new CL.

Acceptable pregnancy rates in embryo transfer are partially dependent upon the onset of estrus in the recipient being within 24-hour synchrony of the embryo donor or stage of development of the embryo (Bó et al., 2012). Pregnancy rates do not differ whether recipients are selected following detection of estrus in untreated animals or estrus synchronization. As estrus in donors will occur 36 to 48 hours after treatment with PGF, recipients must be treated 12 to 24 hours earlier than donors (Bó and Mapletoft, 2014).

\section{Progestins}

Progesterone alters ovarian function in cattle by suppressing estrus and preventing ovulation, primarily by suppressing LH release. As progesterone does not suppress FSH secretion, follicle waves continue to emerge in the presence of a functional CL (Adams, 1999). Progestins given for intervals exceeding the lifespan of a CL result in synchronous estrus upon withdrawal, but fertility is usually low because exogenous progestins are generally less suppressive of LH than endogenous progesterone. The resulting high LH pulse frequency leads to a "persistent" follicle (Savio et al., 1993) with an oocyte that may be infertile (Revah and Butler, 1996).

Progesterone-releasing devices are now used to synchronize estrus in cattle (Mapletoft et al., 2003), and there are several such products available in Brazil and Argentina with different payloads of progesterone for different classes of cattle. Progestin devices are normally removed after 7 or 8 days and PGF is administered at that time (or 24 hours earlier); estrus occurs 48 to 72 hours later. Because of the short treatment period, persistent follicles do not occur and fertility following AI is usually normal. Progestin devices are well suited for the various 
approaches used to synchronize follicular development and ovulation (Mapletoft et al., 2003).

As protocols designed for estrus synchronization have depended on estrus detection, results are often disappointing because estrus detection is time consuming and inaccurate (Washburn et al., 2002). While acceptable conception rates may occur following estrus detection, pregnancy rates are low because of low submission rates. Estrus detection efficiency also affects the use of assisted reproductive technologies e.g., when PGF is used to synchronize cycling recipients in a 2 -injection protocol, $80 \%$ are expected to show signs of estrus within 5 days of the second treatment. However, due to inefficient estrus detection, less than 50\% receive an embryo (Bó et al., 2012). The problem may be greater if the recipients are $B$. indicus or $B$. indicus crosses under pasture conditions (Sartori and Barros, 2011). An alternative is to eliminate the need for estrus detection by applying fixed-time protocols (Baruselli et al., 2010; Bó et al., 2013).

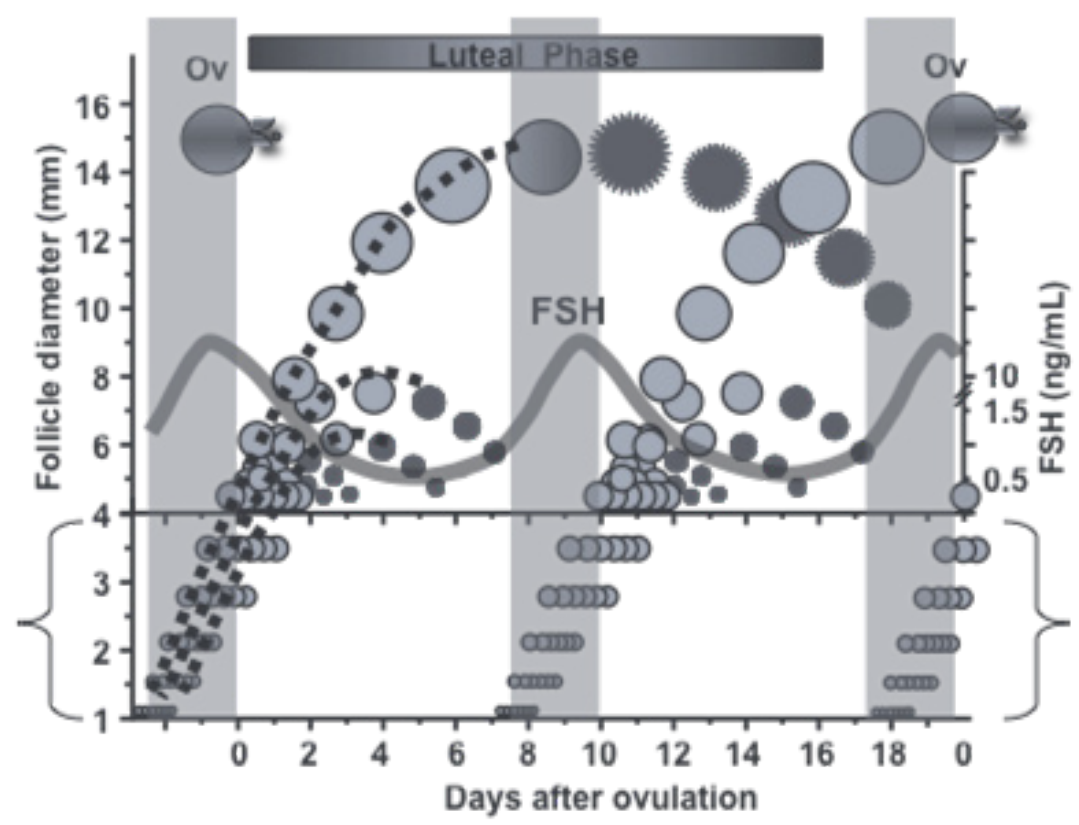

Figure 1. A two-wave ovarian follicular wave pattern detected in follicles as small as $1 \mathrm{~mm}$ in diameter. Small follicles ( 1 to $3 \mathrm{~mm}$ ) in parentheses illustrate wave emergence 2.5 days earlier than previously detected (i.e., at 4 to $5 \mathrm{~mm}$ ). Note that the growth rate of the follicle destined to become dominant (dotted line) is similar to others in the wave until about 5 days after wave emergence at $1 \mathrm{~mm}$, and has a size advantage over those destined to become subordinate as small as $1 \mathrm{~mm}$ in size (Adams et al., 2008). Compliments of GP Adams.

\section{Manipulation of ovarian function for fixed-time AI or fixed-time embryo transfer}

\section{Ultrasound-guided follicle ablation}

Transvaginal ultrasound-guided ablation of antral follicles results in emergence of a new follicular wave in approximately 1.5 days by removing the suppressive effects of follicle products (e.g., estradiol and inhibin) on FSH release (Bergfelt et al., 1994; Fig. 2). Although follicle ablation in combination with PGF is very efficacious in synchronizing follicle wave emergence and ovulation, it is not practical in the field.

\section{Estradiol and progesterone}

Estradiol valerate was originally used at the start of a 9-day progestin protocol to cause uterineinduced luteolysis (Wiltbank et al., 1965), but it has also been shown to suppress antral follicles (Bó et al., 1995). The mechanism of estrogen-induced follicle atresia appears to be systemic, and involves suppression of FSH (Fig. 3). Once exogenously administered estradiol is metabolized, FSH surges and a new follicular wave emerges. The administration of 2.5 to $5 \mathrm{mg}$ estradiol$17 \beta$ (E-17ß; reviewed in Bó et al., 2002) or $2 \mathrm{mg}$ of estradiol benzoate (EB; Martinez et al., 2005) or estradiol valerate (EV; Colazo et al., 2005) in progestintreated cattle results in emergence of a new follicular wave in 3 to 5 days.

In early estrus synchronization protocols, $2.5 \mathrm{mg}$ EB is administered at the time of insertion of a progestin device which is removed 7 days later, at the time of administration of PGF (Mapletoft et al., 2003). A dose of $1 \mathrm{mg}$ EB was given 24 hours later to induce an LH surge in 16 to 18 hours (Martinez et al., 2007) and ovulation approximately 24 hours later. This permitted FTAI with acceptable pregnancy rates. As an alternative, administration of 0.5 to $1.0 \mathrm{mg}$ of estradiol cypionate (ECP; Colazo et al., 2003) at the time of progestin removal with FTAI 48 to 52 hours later is often used in South America (Sales et al., 2012: Martins et al., 2017). Pregnancy rates following FTAI have been shown to be improved in suckled beef cows and heifers, especially $B$. indicus crosses, when 300 to $400 \mathrm{IU}$ of $\mathrm{eCG}$ is administered at the time of progestin removal (Baruselli et al., 2004; Bó et al., 2012; 2016). The administration of eCG stimulates dominant follicle growth and 
maturation, and increases progesterone production by the subsequent CL (B. taurus, Nunez-Olivera et al., 2014; B. indicus, Baruselli et al., 2004). Estradiol, progesterone and eCG treatments are also very useful for fixed-time embryo transfer (FTET) with a greater proportion of recipients selected for embryo transfer and higher pregnancy rates following transfer (Baruselli et al., 2010; Bó et al., 2012; Rodrigues et al., 2010).

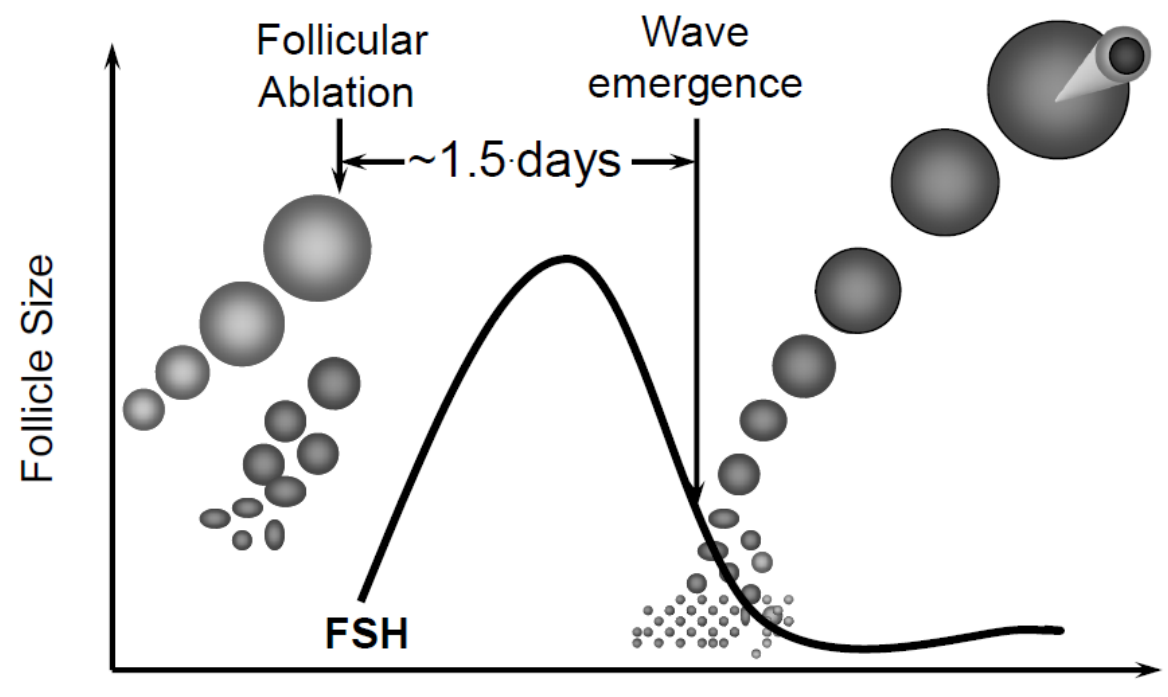

Days

Figure 2. Synchronization of follicular wave emergence by ultrasound-guided follicle ablation. Aspiration of antral follicles causes the emergence of the next follicular wave by removing the suppressive effects of follicle products on FSH release. FSH surges and follicular wave emergence occurs 1 to 2 days later.

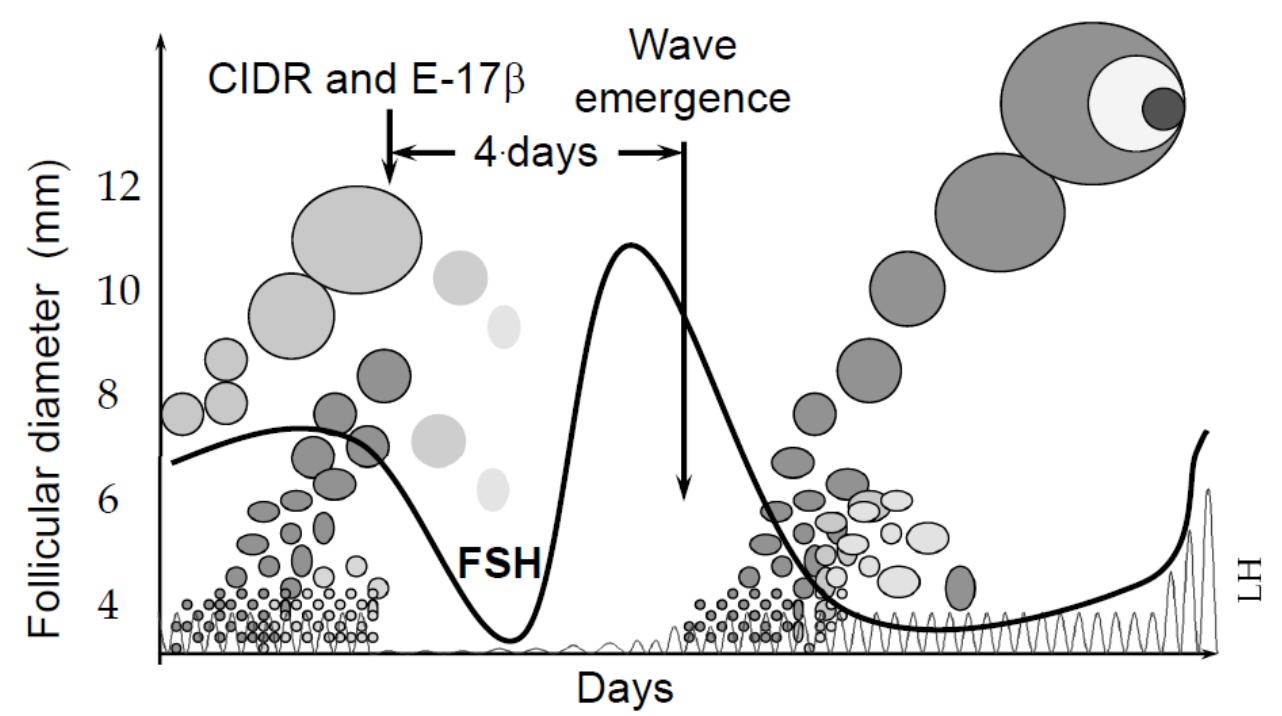

Figure 3. Synchronization of follicular wave emergence by estradiol/progestin treatment. Estradiol causes suppression of FSH and atresia of FSH-dependent follicles. Once the injected estradiol is metabolized, FSH surges and a new follicular wave emerges 3 to 5 days after treatment.

Gonadotropin releasing hormone (GnRH)

GnRH treatment of cattle with a growing dominant follicle will induce ovulation and emergence of a new follicular wave 1 to 2 days later (Macmillan and Thatcher, 1991) by inducing LH release, but only when ovulation occurs (Martinez et al., 1999; Fig. 4). An ovulation synchronization protocol for FTAI in lactating dairy cattle utilizing $\mathrm{GnRH}$ has been developed by Pursley et al. (1995; Ovsynch). Administration of GnRH is followed in 7 days by PGF and a second GnRH in 48 hours, with FTAI 16 to 18 hours later. More recently, it has been shown that pregnancy per $\mathrm{AI}(\mathrm{P} / \mathrm{AI})$ is improved in lactating dairy cattle if the interval from PGF to the second $\mathrm{GnRH}$ is increased to 56 hours (Ovsynch-56; Brusveen et al., 2008). The Ovsynch protocol has been more efficacious in lactating dairy cows than in heifers (Seguin, 1997). Although the cause is not clear, ovulation following the first GnRH has been reported to be higher in cows than heifers and a higher percentage of heifers show estrus early, resulting in reduced fertility following FTAI 
(Wiltbank, 1997).

Stage of development of the dominant follicle (Martinez et al., 1999), and stage of the estrous cycle (Vasconcelos et al., 1999; Moreira et al., 2000) affect response to the first GnRH. If the dominant follicle is immature or post-mature, ovulation may not occur and a new follicular wave will not emerge. Cattle respond most consistently between Days 5 and 12 of the estrous cycle, so a 2-injection PGF pre-synchronization treatment is often used before administration of the first GnRH (Moreira et al., 2001). Various other presynchronization protocols have been developed to improve P/AI following the use of the Ovsynch protocol (Stevenson, 2011). Alternatively, a progestin insert at the time of the first GnRH has also improved P/AI in beef heifers (Martinez et al., 2002), beef cows (Lamb et $a l ., 2001$ ) and anovulatory dairy cows (Stevenson et al., 2006; Bisinotto et al., 2013). Treatment with eCG at the time of progestin removal has also improved pregnancy rates in non-cycling beef cows (Bó et al., 2016).

More recently, a 5-day GnRH-based, Co-Synch protocol has been developed for beef cattle in North America, with higher P/AI than obtained with the more traditional 7-day Co-Synch protocol (Bridges et al., 2008; reviewed in Day, 2015). The physiological basis of this protocol is to reduce the progestin device insertion period to 5 days, avoiding the development of persistent follicles in cattle not ovulating to the first $\mathrm{GnRH}$, and then lengthening the proestrus period to 72 hours to allow for greater dominant follicle development and higher circulating estrogen levels prior to ovulation. However, two injections of PGF are required with this protocol to induce luteal regression in animals that ovulate to the first GnRH. Several subsequent studies have been designed to eliminate the need for extra animal handling associated with two injections of PGF, but results have been inconsistent, possibly because of the inconsistent response to the first GnRH in heifers. Rabaglino et al. (2010) found no difference in $\mathrm{P} / \mathrm{AI}$, whether one or two injections of PGF were administered, while Peterson et al. (2011) reported that heifers given two injections of PGF tended to have higher P/AI. Colazo and Ambrose (2011) eliminated the initial administration of GnRH in the 5day protocol without adversely affecting fertility. However, in a large study, Lima et al. (2013) found that $\mathrm{P} / \mathrm{AI}$ was greater in heifers that received $\mathrm{GnRH}$ at progestin insertion and two injections of PGF after progestin removal (on Days 5 and 6) than in heifers that did not receive the initial GnRH, whether they received one or two injections of PGF. More recently, Kasimanickam et al. (2014) reported that the initial GnRH increased P/AI in beef heifers, but not in dairy heifers, and that P/AI in dairy heifers did not differ whether they received one or two injections of PGF. Perhaps, it is simply a matter of statistical power. In Argentina, an estradiol-based protocol with shortened progestin exposure and a lengthened proestrus, named JSynch, has been developed (reviewed in Bó et al., 2016). This protocol has the advantage that an initial GnRH treatment (and subsequently, two injections of PGF) is not required. Use of a 6-day J-Synch protocol has resulted in higher $\mathrm{P} / \mathrm{AI}$ in heifers than the conventional 8day estradiol-based protocol (Bó et al., 2016).

GnRH-based protocols are also efficacious in the synchronization of ovulation in recipients (Bó et al., 2012). In B. indicus $\times$ B B. taurus crossbred heifers, the overall pregnancy rate was higher in recipients treated with a 7-day GnRH-based protocol than with PGF alone, because more recipients had a CL on the day of embryo transfer (Baruselli et al., 2010). The inclusion of a progestin device in a 7-day $\mathrm{GnRH}$-based protocol in embryo recipients has also resulted in higher pregnancy rates (Beal, 1999). In a field trial involving 1637 recipients treated with GnRH plus a CIDR device and without estrus detection, overall pregnancy rate following embryo transfer to recipients with a CL was $59.9 \%$. The beneficial effects of the J-Synch protocol on fertility has been confirmed recently in a recipient synchronization program (Bó et al., 2016).

\section{Manipulation of ovarian function for superstimulation}

The objective of ovarian superstimulatory treatments in cattle is to obtain the maximum number of viable embryos by stimulating growth of antral follicles and ovulation of competent oocytes (Bó and Mapletoft, 2014). Two very important factors influencing variability in superstimulatory response are the intrinsic number of antral follicles in donors, and the stage of follicular development at the time of initiating FSH treatments. Response can be predicted by antral follicle counts done with ultrasonography (Singh et al., 2004; Ireland et al., 2008), or measurement of circulating concentrations of anti-Müllerian hormone (AMH; $B$. taurus, Rico et al., 2009; Ireland et al., 2011; B. indicus, Batista et al., 2014). High antral follicle counts resulted in more ovulations and a greater number of transferable embryos than low antral follicle counts (Ireland et al., 2007). Similarly, the top quartile of circulating AMH values was associated with a greater superovulatory response than the lowest quartile (Souza et al., 2014).

The conventional protocol of initiating ovarian superstimulation during mid-cycle has been based on anecdotal and experimental evidence suggesting a greater superovulatory response when gonadotropin treatments were initiated between Days 8 and 12 of the cycle (Bó and Mapletoft, 2014). It is now known that mid-cycle is the approximate time of emergence of the second follicular wave (Ginther et al., 1989b). However, day of second wave emergence varies between wave types ( 1 or 2 days later in 2-wave cycles than in 3-wave cycles). In this regard, Nasser et al. (1993) showed that superovulatory response was greater when gonadotropin treatments were initiated at the time of follicle wave emergence; 1-day asynchrony reduced the response. The necessity of waiting until mid-cycle to initiate FSH treatment implies monitoring estrus, the obligatory delay and an inability to group donors. An alternative is to superstimulate donors following synchronization of follicular wave emergence (Bó et al., 1995; 2002; 2014). 


\section{Follicle ablation}

Transvaginal ultrasound-guided follicle ablation followed by FSH treatments 1 or 2 days later is very efficacious (Bergfelt et al., 1997), but requires specialized skill and equipment and is difficult to apply in the field. However, follicle aspiration for OPU/IVF will synchronize wave emergence and thus, embryos could be produced both in vitro and in vivo, from the same donor (Surjus et al., 2014).

\section{Estradiol and progesterone}

The preferred approach for synchronization of follicular wave emergence prior to superstimulation is administration of $5 \mathrm{mg}$ E- $17 \beta$ plus $100 \mathrm{mg}$ progesterone and insertion of a progestin device 4 days before initiating FSH treatments. Experimental (Bó et al., 1996) and commercial (Bó et al., 2002) results have shown that embryo production following this treatment at unknown stages of the estrous cycle is comparable to that initiated 8 to 12 days after observed estrus. By synchronizing follicle wave emergence, the full extent of the estrous cycle is available and the need to detect estrus and wait 8 to 12 days to initiate FSH treatments was eliminated. Although E-17 $\beta$ and its esters are available in most, if not all, countries in South America, this is not the case in many other countries around the world necessitating the use of alternatives to synchronize follicle wave emergence prior to superstimulation.

\section{Gonadotropin releasing hormone}

Attempts to synchronize follicular wave emergence for superstimulation with GnRH were initially unsuccessful; however, subsequent field data were more promising. In these cases, GnRH was administered 1.5 to 3.0 days after the insertion of a progestin device which may have increased the probability of an LH-responsive follicle. Indeed, Bó et al. (2008) reported on the strategic use of PGF, a progestin device and GnRH to induce ovulation prior to initiating FSH treatments. Basically, a persistent follicle was induced by treatment with PGF at the time of progestin device insertion; following administration of GnRH 7 days later; ovulation occurred in more than $95 \%$ of animals. Superstimulation initiated 36 hours after GnRH (with the progestin device remaining in place) resulted in a superovulatory response that did not differ from controls. More recently, Hinshaw et al. (2015) reported no difference in superovulatory response whether GnRH was administered 2 or 7 days after insertion of a progestin device.

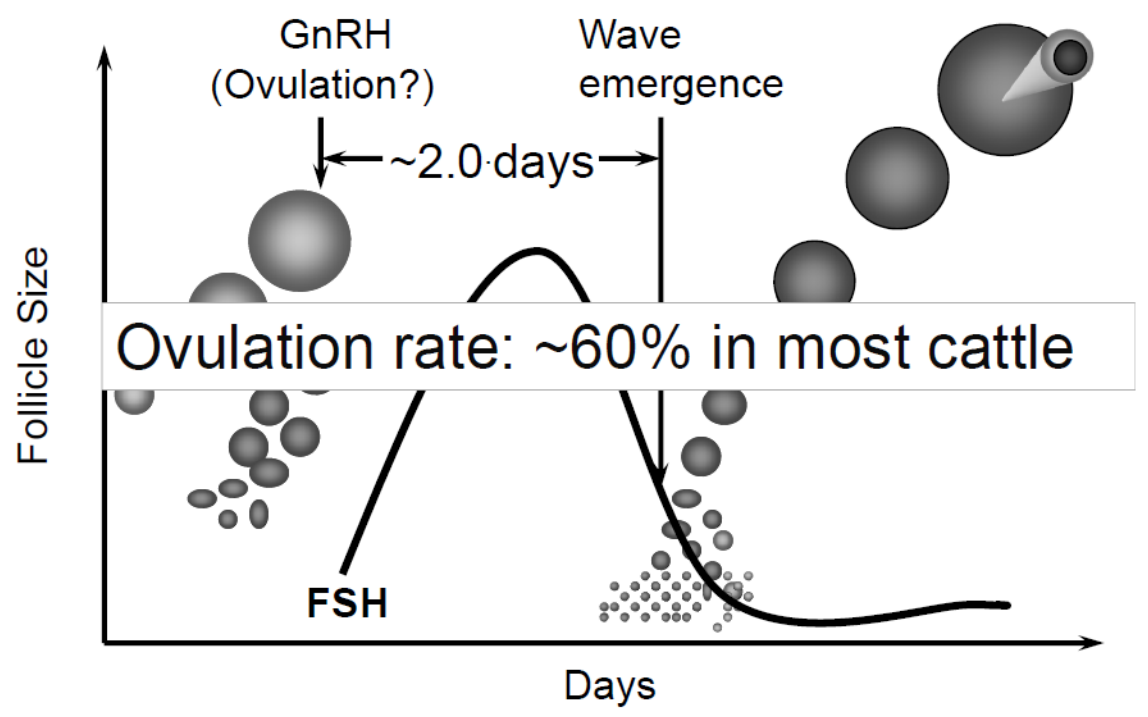

Figure 4. Synchronization of follicular wave emergence by GnRH treatment which causes ovulation of a growing dominant follicle. This removes the suppression of follicle products on FSH release; FSH surges and a new follicle wave emerges approximately 2 days after treatment. However, treatment at random stages of the estrous cycle results in less than $60 \%$ of animals ovulating and if ovulation does not occur, follicle wave emergence will not be synchronized.

\section{The ruminant reproduction revolution in South America}

South American countries are world leaders in beef production, while only Uruguay and possibly Argentina, have dairy industries large enough to exceed local demands. In 2016, Latin American countries had approximately 359 million cattle (accounting for $24 \%$ of the world's cattle population) and produced 15.1 million tonnes of beef (Food and Agriculture Organization of the United Nations-FAO, January, 2018). Brazil had 218.2 million cattle and produced 9.3 million tonnes of beef in 2016. Of the main beef-producing countries in South America, Brazil (60.8\% of the total), Argentina $(14.7 \%)$ and Uruguay $(3.3 \%)$ are also prominent in development and application of assisted reproductive biotechnologies. Through training and continuing education programs, many of which one or more of the authors have organized or participated in, these technologies are being used increasingly in other South 
American countries. It is through these efforts, in partnership with the pharmaceutical industry, that the ruminant reproductive revolution in South America has become widespread.

It is not possible in this manuscript to discuss all the contributions of South American scientists to the increased and improved understanding of bovine reproduction, especially in $B$. indicus breeds, nor describe in detail the application of reproductive biotechnologies in their breeding herds. However, the reference list in this manuscript (and many other similar publications) provides names of many South American nationals who have made important contributions. Brazil and Argentina, in particular, are very active in research, continuing education and post-graduate student training in reproductive biotechnology, especially in cattle.

Application of assisted reproductive technologies (Sartori et al., 2016b), and the state of the embryo transfer (Viana et al., 2017) and AI (Baruselli et al., 2017) industries in Brazil have been reviewed very recently. Therefore, this paper will focus on Brazil, recognizing that similar advances are taking place in other South American countries, especially Argentina and Uruguay.

The commercial embryo transfer industry began in North America in the early 1970s, and the technology soon spread to South America (Mapletoft, 2013). Although IVD bovine embryo numbers remained modest for several years, Brazil and Argentina consistently ranked in the top five countries outside North America and Europe. Perry (2017) has reported that in 2016 more than 632,000 IVD and 666,000 IVP bovine embryos were produced world-wide. North America accounted for more than $52 \%$ of the IVD embryos, but South America accounted for more than $57 \%$ of the IVP embryos. The use of IVP in Brazil has increased rapidly since 2000 , driven primarily by $B$. indicus breeds which have large numbers of antral follicles from which large numbers of high quality oocytes can be recovered, without superstimulation Viana et al. (2017) reported that embryo transfer accounted for $19.7 \%$ of all "Zebu" calves registered in Brazil between 2005 and 2015. In vitro embryo production in Brazil increased by $184.0 \%$ between 2005 and 2016, while numbers of IVD embryos decreased by 73.7\% (Fig. 5; Viana, personal communication, 2017).

Commercial IVP in Brazil has been reported to have gone through three phases (Sartori et al., 2016b). The initial phase involved the use of proven donors of high genetic merit in both beef and dairy cattle, and the numbers of IVD and IVP embryos increased similarly. The second phase of growth occurred between 2003 and 2010 , driven largely by the need to produce replacement bulls. In 2005, at the peak of this phase, $90.0 \%$ of IVP was in beef breeds with Nelore accounting for $82.7 \%$ of all embryos. The third phase has involved the use of sex-selected sperm and is associated with a shift in IVP from beef breeds to B. taurus dairy breeds. In 2014, IVP in dairy breeds increased by $46.5 \%(69.0 \%$ of the total $)$, exceeding that of beef breeds for the first time.

A similar example of the application of assisted reproductive technologies involves the utilization of
FTAI in cattle breeding. Most beef herds in Brazil are composed of $B$. indicus or $B$. indicus crosses, while Argentina and Uruguay tend to have more $B$. taurus breeds and their crosses. It is noteworthy that $B$. indicus breeds tend to have long periods of postpartum anestrus and low body condition scores on pasture, with an increased interval from calving to conception and low fertility (Bó et al., 2003). In a pasture-based cow-calf production system, synchronization protocols are necessary to produce pregnancies by AI during a short breeding season and because of problems with estrus detection, FTAI has been incorporated (Bó et al., 2013; 2016). Breeding objectives have been to inseminate early in the breeding season followed by early ultrasonographic pregnancy diagnosis and reinsemination of open cattle as soon as possible (Baruselli et al., 2017).

Because estradiol preparations have been available in South America, most FTAI protocols include estradiol as a means of synchronizing follicle wave emergence and ovulation (Bó et al., 2013). As herd cyclicity and body condition scores are usually low, progestin devices and eCG are usually included in the synchronization protocols (Baruselli et al., 2012; Bó et al., 2016). To minimize animal handling and the suppressive effect of progesterone on follicle growth, PGF is often administered at the beginning of the protocol, and ECP is administered at the time of progestin device removal (rather than EB 1 day later) with FTAI 48 hours later. Protocols of $6,7,8$ or 9 days progestin treatment have resulted in similar $\mathrm{P} / \mathrm{AI}$, and shortened progestin protocols with a lengthened proestrus involving either estradiol or $\mathrm{GnRH}$ have been used with success (Bó et al., 2016). The administration of PGF on Day 7 (1 day before progestin removal) in dairy cows has increased P/AI following either FTAI or FTET (Pereira et al., 2013). The benefits of eCG in FTET treatment protocols have also been shown in crossbred recipients (Baruselli et al., 2010; Bó et al., 2012) and high-producing dairy cows (Rodrigues et al., 2010).

Resynchronization protocols have also been developed to reduce the interval between FTAI and reinsemination of nonpregnant animals (Bó et al., 2016) Traditionally, resynchronization has been done at pregnancy diagnosis 28 to 32 days after FTAI, with a breeding interval of approximately 40 days. Two recent protocols, developed in Brazil, beginning before pregnancy diagnosis (14 or 22 days after the FTAI) have reduced the interval between FTAI and reinsemination to 24 and 32 days, respectively (reviewed in Baruselli et al., 2017). The novelty of the 14-day protocol is the use of Doppler ultrasonography 22 days after FTAI for pregnancy diagnosis; a CL area of $\geq 2 \mathrm{~cm}^{2}$ and/or CL blood flow of $\geq 25 \%$ are diagnostic of pregnancy. Resynchronization protocols have led to the adoption of management schemes exclusively for FTAI, eliminating the need for clean-up bulls. In one study, a cumulative pregnancy rate of $87.4 \%$ was achieved after three FTAI in a 64-day breeding season, which was greater than achieved with bull exposure after one FTAI (reviewed in Baruselli et al., 2017).

Data also indicate that FTAI is increasing the 
use of AI, especially with $B$. indicus sires on $B$. indicus cows in Brazil. There has been more than a 10-fold increase in the use of FTAI in Brazil, from $\sim 1$ million protocols in 2005 ( $11 \%$ of all $\mathrm{AI})$ to 10.5 million protocols in 2015 (77\% of all AI; Sartori et al., 2016b), and a further increase to more than 11 million FTAI in 2016 (Baruselli et al., 2017; Fig. 6). Currently, FTAI procedures account for $85 \%$ of AI performed in Brazil. In addition, the proportion of dairy cows not inseminated by 70 DIM has decreased resulting in more cows pregnant by 103 DIM and a decrease of approximately 35 days open (Sartori et al., 2016b). Industry reports from Argentina and Uruguay for the 2016/17 breeding season indicate a similar trend, especially in beef cattle (3 million and 300,000 FTAI, respectively, representing approximately $10 \%$ of their breeding herds). In total, more than 15 million cattle were inseminated by FTAI in these three countries over the past year. Baruselli et al. (2017) suggested that the adoption of this technology is an excellent example of a technological change in the production sector emerging from scientific developments in the academic sector.

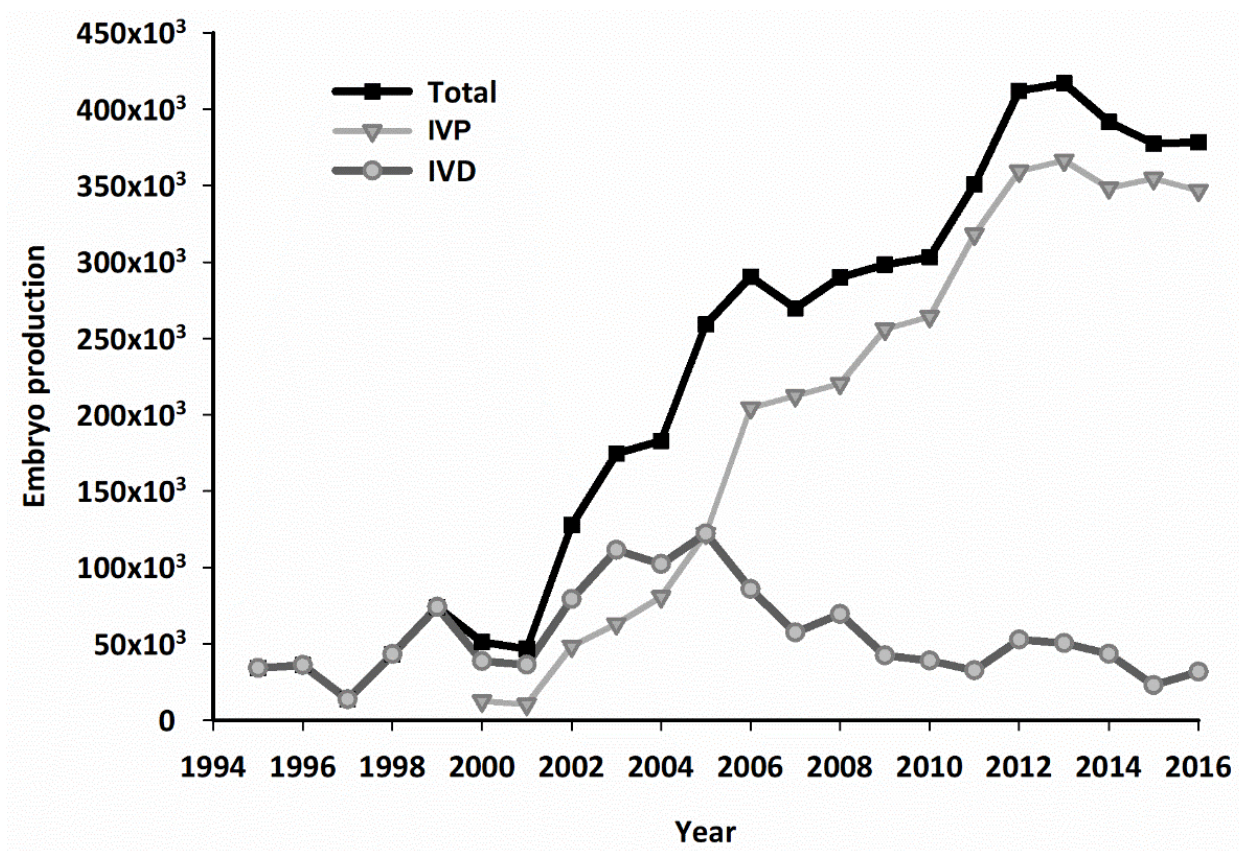

Figure5. Production of bovine embryos in Brazil from 1995 to 2016. Numbers of embryos produced are shown as Total (in vivo and in vitro embryos combined); IVP (embryos produced in vitro; OPU/IVF); IVD (embryos produced in vivo; superovulation and collection). Note that beginning in 2005 numbers of IVP embryos exceeded numbers of IVD embryos and the numbers of IVD embryos began to decline. Complements of Dr. JHM Viana.

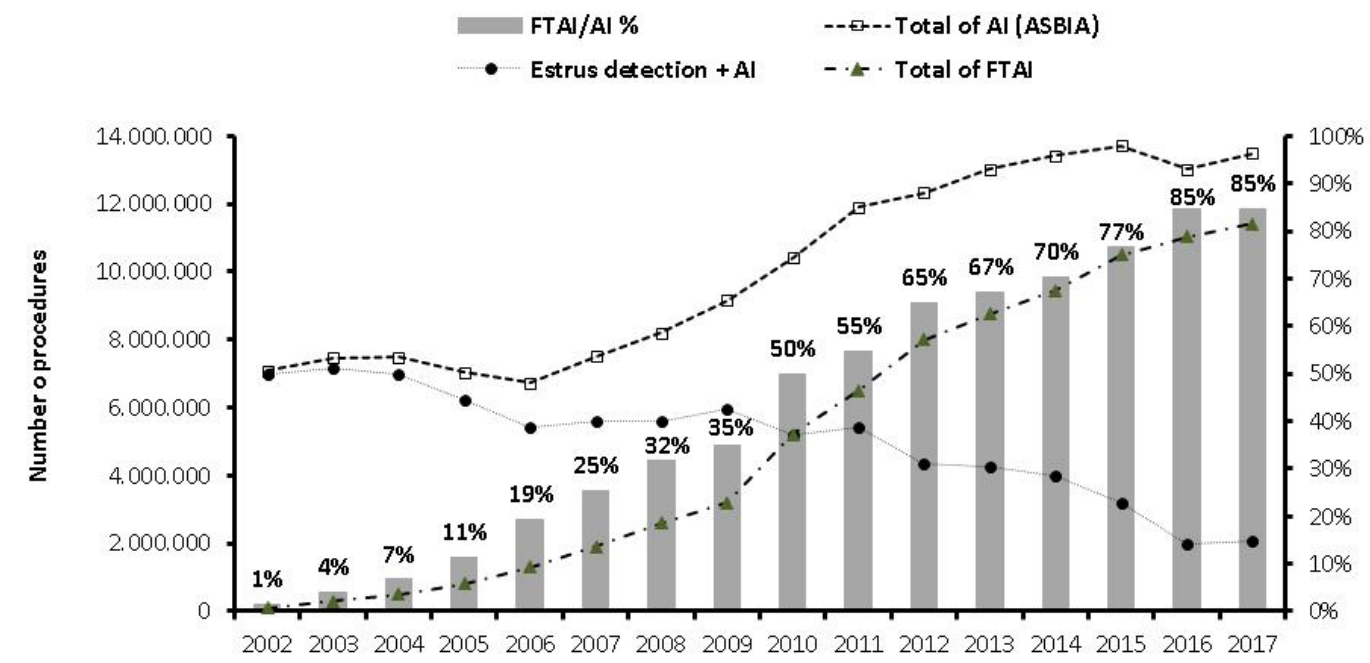

Figure 6. Illustration of the increased use of artificial insemination (AI) and fixed-time AI (FTAI) in Brazil. The numbers of AI were done after estrus detection, while the numbers of FTAI are an estimate based on the number of protocols sold (information provided by pharmaceutical companies in the sector) and the total number of AI is based on the numbers of semen straws sold (*ASBIA, 2017). Data were organized by Departamento de Reprodução Animal-FMVZ-USP, São Paulo, Brazil, 2017. Adapted from Baruselli et al., 2017. *ASBIA (Brazilian Artificial Insemination Association). 


\section{Financial benefits of the ruminant reproductive revolution in Brazil}

It is estimated that the impact of FTAI on the dairy and beef industries in Brazil is $\sim \mathrm{U} \$ 800$ million of extra income per year (Baruselli et al., 2017). The use of FTAI has resulted in an estimated 3,500 veterinarians being directly involved with $\sim$ U\$175 million of economic activity, and there has been an increase of $8 \%$ in calf production, representing an additional income of U $\$ 253$ million. Thus, FTAI in Brazil has increased income in the beef production chain by more than a half billion U\$ per year. In the dairy industry, FTAI has added U\$278 million per year by reducing calving intervals and increasing the use of genetically improved sires. It is estimated that FTAI has reduced the calving interval by 30 days and increased annual milk production by $10 \%$, resulting in $\sim \mathrm{U} \$ 234$ million of additional income per year for dairy producers.

\section{Future considerations for continued development of the embryo transfer industry}

Despite the considerable progress made in the application of bovine embryo transfer technologies in South America over the past two decades, especially with IVP in Brazil, donor selection has leaned heavily on phenotypic traits. For real genetic gain, generation intervals must be shortened, selection intensity must be increased and the accuracy of selection must be improved (Smith 1988). Genomic techniques have now become essential for the selection of donors (male and female) used in embryo transfer (Ponsart et al. 2014). In the dairy industry, genetic progress has been accelerated by the use of embryo transfer combined with genomic selection. This could have an even greater impact in the beef industry, as genomic traits for beef production are further developed.

Although the use IVP embryos in South America has increased greatly over the past 15 years, a major limitation has been that most IVP embryos had to be transferred fresh. Cryopreservation of IVP embryos, especially within $B$. indicus breeds, has been very difficult. Although improvements in culture conditions and embryo grading systems will likely increase success with cryopreservation, a recent publication by Sanches et al. (2016) provides convincing evidence that the Direct Transfer of frozen/thawed IVP embryos can result in satisfactory pregnancy rates. With continued improvements in this technology, the use of cryopreserved IVP embryos will no doubt increase.

Sex-selected sperm in the production of IVP embryos has obvious advantages, especially with the recent increase in the use of IVP in the generation of dairy embryos. However, Siqueira et al. (2017) have recently reported that the use of reverse X-sorted spermatozoa in the production of IVP embryos resulted in an alteration of embryonic programming that persisted postnatally and caused an effect on milk production in adulthood. Thus, benefits of the use of sex-selected semen in the production of IVP embryos could be offset by adverse programming events. It is not known whether regular sexing technologies have similar effects, and whether this effect can be overcome. Obviously, this finding raises concerns that must be resolved.

\section{Summary and conclusions}

The ability to control follicular wave emergence and ovulation in cattle has eliminated the need for estrus detection allowing for FTAI and FTET, and the initiation of superstimulation of embryo donors on predetermined schedules. In addition, the utilization of eCG in these protocols has increased pregnancy rates, especially in cattle experiencing postpartum anestrus. Practitioners in most South American countries are utilizing these protocols which has facilitated the application of assisted reproductive technologies. The utilization of FTAI has resulted in great increases in the use of AI, and the adaption of these protocols for FTET has increased the use of bovine embryo transfer, especially with IVP embryos. Currently, FTAI procedures account for $85 \%$ of all AI done in Brazil, and a similar trend is occurring in Argentina and Uruguay. Although the numbers of IVD embryos has tended to decrease, especially in Brazil, IVP has increased greatly with more than $57 \%$ of all IVP embryos in the world produced in South America. There has been a remarkable shift in the use of IVP from beef breeds to dairy breeds in Brazil, with only a modest decrease in embryo production. Collectively, the successful application of assisted reproductive technologies in South America is resulting in the dissemination of new and improved genetics and increased reproductive performance in all classes of cattle, with a corresponding increase in economic activity.

\section{Acknowledgements}

The authors thank Drs. GP Adams for Figure 1 and JHM Viana for Figure 4. Thanks also to Vetoquinol Inc. for support of Mapletoft and Bó.

\section{References}

Adams GP. 1999. Comparative patterns of follicle development and selection in ruminants. $J$ Reprod Fertil Suppl, 54:17-32.

Adams GP, Jaiswal R, Singh J, Malhi P. 2008. Progress in understanding ovarian follicular dynamics in cattle. Theriogenology, 69:72-80.

Bao B, Garverick HA. 1998. Expression of steroidogenic enzyme and gonadotropin receptor genes in bovine follicles during ovarian follicular waves: a review. J Anim Sci, 76:1903-1921.

Baruselli PS. Reis EL, Marques MO, Nasser LF, Bó GA. 2004. The use of hormonal treatments to improve reproductive performance of anestrous beef cattle in tropical climates. Anim Reprod Sci, 82-83:479-486.

Baruselli PS, RM Ferreira, Filho MF, Nasser LFT, Rodrigues CA, Bó GA. 2010. Bovine embryo transfer recipient synchronization and management in tropical environments. Reprod Fertil Dev, 22:67-74.

Baruselli PS, Sa' Filho MF, Ferreira RM, Sales JNS, Gimenes LU, Vieira LM, Mendanha MF, Bó GA. 
2012. Manipulation of follicle development to ensure optimal oocyte quality and conception rates in cattle. Reprod Dom Anim, 47(Suppl 4):134-141.

Baruselli Pietro Sampaio, Ferreira Roberta Machado, Colli Marcos Henrique Alcantara, Elliff Flávia Morag, Sá Filho Manoel Francisco, Vieira Lais, Gonzales de Freitas Bruno. 2017. Timed artificial insemination: current challenges and recent advances in reproductive efficiency in beef and dairy herds in Brazil. Anim Reprod, 14:558-571.

Batista EOS, Macedo GG, Sala RV, Ortolan MDDV, Sa Filho MF, Del Valle TA, Jesus EF, Lopes RNVR, Renno FP, Baruselli PS. 2014. Plasma antimullerian hormone as a predictor of ovarian antral follicular population in Bos indicus (Nelore) and Bos taurus (Holstein) heifers. Reprod Dom Anim, 49:448-452.

Beal WB. 1999. Streamlining embryo transfer. In: Proceedings of the 18th Annual Convention AETA, Colorado Springs, CO, USA. Savoy, IL: AETA. pp.7885.

Bergfelt DR, Lightfoot KC, Adams GP. 1994. Ovarian dynamics following ultrasound-guided transvaginal follicle ablation in heifers. Theriogenology. 42:895-907.

Bergfelt DR, Bó GA, Mapletoft RJ, Adams GP. 1997. Superovulatory response following ablation-induced follicular wave emergence at random stages of the estrous cycle in cattle. Anim Reprod Sci, 49:1-12.

Bisinotto RS, Ribeiro ES, Lima FS, Martinez N, Greco LF, Barbosa LFSP, Bueno PP, Scagion LFS, Thatcher WW, Santos JEP. 2013. Targeted progesterone supplementation improves fertility in lactating dairy cows without a corpus luteum at the initiation of the timed artificial insemination protocol. $J$ Dairy Sci, 96:2214-2225.

Bó GA, Adams GP, Pierson RA, Mapletoft RJ. 1995. Exogenous control of follicular wave emergence in cattle. Theriogenology, 43:31-40.

Bó GA, Adams GP, Pierson RA, Mapletoft RJ. 1996. Effect of progestogen plus E-17 $\beta$ treatment on superovulatory response in beef cattle. Theriogenology, 45:897-910

Bó GA, Baruselli PS, Moreno D, Cutaia L, Caccia M, Tribulo R, Tribulo H, Mapletoft RJ. 2002. The control of follicular wave development for selfappointed embryo transfer programs in cattle. Theriogenology, 57:53-72.

Bó GA, Baruselli PS, Martinez MF. 2003. Pattern and manipulation of follicular development in Bos indicus cattle. Anim Reprod Sci, 78:307-326.

Bó GA, Carballo Guerrero D, Adams GP. 2008. Alternative approaches to setting up donor cows for superstimulation. Theriogenology, 69:81-87.

Bó G A, Peres LC, Cutaia LE, Pincinato D, Baruselli PS, Mapletoft RJ. 2012. Treatments for the synchronisation of bovine recipients for fixed-time embryo transfer and improvement of pregnancy rates. Reprod Fertil Dev, 24:272-277.

Bó GA, Baruselli PS, Mapletoft RJ. 2013. Synchronization techniques to increase the utilization of artificial insemination in beef and dairy cattle. Anim Reprod, 10:137-143.
Bó Gabriel A, Mapletoft Reuben J. 2014. Historical perspectives and recent research on superovulation in cattle. Theriogenology, 81:38-48.

Bó GA, de la Mata JJ, Baruselli PS, Menchaca A. 2016 Alternative programs for synchronizing and resynchronizing ovulation in beef cattle. Theriogenology, 86:388-396.

Bridges GA, Helser LA, Grum DE, Mussard ML, Gasser CL, Day ML. 2008. Decreasing the interval between GnRH and PGF $2 \alpha$ from 7 to 5 days and lengthening proestrus increases timed-AI pregnancy rates in beef cows. Theriogenology, 69:843-851.

Brusveen DJ, Cunha AP, Silva CD, Cunha PM, Sterry RA, Silva EPB, Guenther JN, Wiltbank MC. 2008. Altering the time of the second gonadotropinreleasing hormone injection and artificial insemination (AI) during Ovsynch affects pregnancies per AI in lactating dairy cows. J Dairy Sci, 91:1044-1052.

Colazo MG, Martínez MF, Kastelic JP, Mapletoft RJ 2003. Effects of estradiol cypionate (ECP) on ovarian follicular dynamics, synchrony of ovulation, and fertility in CIDR-based, fixed-time AI programs in beef heifers. Theriogenology, 60:855-865.

Colazo MG, Martínez MF, Small JA, Kastelic JP, Burnley CA, Ward D. Mapletoft RJ. 2005. Effects of estradiol valerate on ovarian follicle dynamics and superovulatory response in progestin-treated cattle. Theriogenology, 63:1454-1468.

Colazo MG, Ambrose DJ. 2011. Neither duration of progesterone insert nor initial GnRH treatment affected pregnancy per timed-insemination in dairy heifers subjected to a Co-synch protocol. Theriogenology, 76:578-588.

Day ML. 2015. State of the art of GnRH-based timed AI in beef cattle. Anim Reprod, 12:473-478.

Folman Y, Kaim M, Herz Z, Rosenberg M. 1990. Comparison of methods for the synchronization of estrous cycles in dairy cows. 2. Effects of progesterone and parity on conception. J Dairy Sci, 73:2817-2825.

García Guerra A, Tribulo A, Yapura J, Adams GP, Singh J, Mapletoft RJ. 2015. Lengthened superstimulatory treatment in cows: evidence for rescue of follicles within a wave rather than continuous recruitment of new follicles. Theriogenology, 84:467476.

Gimenes LU, Sá Filho MF, Carvalho NAT, TorresJunor JRS, Souza AH, Madureira EH, Tricia LA, Sartorelli ES, Barros CM, Carvalho JBP, Mapletoft RJ, Baruselli PS. 2008. Follicle deviation and ovulatory capacity in Bos indicus heifers. Theriogenology, 69:852-858.

Ginther OJ, Kastelic JP, Knopf L. 1989a. Composition and characteristics of follicular waves during the bovine estrous cycle. Anim Reprod Sci, 20:187-200.

Ginther OJ, Knopf L, Kastelic JP. 1989b. Temporal associations among ovarian events in cattle during oestrous cycles with two and three follicular waves. $J$ Reprod Fert, 87:223-230

Ginther OJ, Bergfelt DR, Beg MA, Kot K. 2001. Follicle selection in cattle: relationships among growth rate, diameter ranking, and capacity for dominance. Biol 
Reprod, 65:345-350.

Hinshaw RH, Switzer ML, Mapletoft RJ, Bó GA. 2015. A comparison of 2 approaches for the use of $\mathrm{GnRH}$ to synchronize follicle wave emergence for superovulation. Reprod Fertil Dev, 27:263. (Abstract).

Ireland JJ, Ward F, Jimenez-Krassel F, Ireland JLH, Smith GW, Lonergan P, Evans ACO. 2007. Follicle numbers are highly repeatable within individual animals but are inversely correlated with FSH concentrations and the proportion of good-quality embryos after ovarian stimulation in cattle. Hum Reprod, 22:1687-1695.

Ireland JLH, Scheetz D, Jimenez-Krassel F, Themmen APN, Ward F, Lonergan P, Smith GW, Perez GI, Evans ACO, Ireland JJ. 2008. Antral follicle count reliably predicts number of morphologically healthy oocytes and follicles in ovaries of young adult cattle. Biol Reprod, 79:1219-1225.

Ireland JJ, Smith GW, Scheetz D, Jimenez-Krassel F, Folger JK, Ireland JL, Mossa F, Lonergan P, Evans AC. 2011. Does size matter in females? An overview of the impact of the high variation in the ovarian reserve on ovarian function and fertility, utility of anti-Müllerian hormone as a diagnostic marker for fertility and causes of variation in the ovarian reserve in cattle. Reprod Fertil Dev, 23:1-14.

Kasimanickam RK, Firth P, Schuenemann GM, Whitlock BK, Gay JM, Moore DA, Hall JB, Whittier WD. 2014. Effect of the first GnRH and two doses of PGF2 $\alpha$ in a 5-day progesterone-based CO-Synch protocol on heifer pregnancy. Theriogenology, 81:797-804.

Kastelic JP, Knopf L, Ginther OJ. 1990. Effect of day of prostaglandin F2 $\alpha$ treatment on selection and development of the ovulatory follicle in heifers. Anim Reprod Sci, 23:169-180.

Kastelic JP, Ginther OJ. 1991. Factors affecting the origin of the ovulatory follicle in heifers with induced luteolysis. Anim Reprod Sci, 26:13-24.

Lamb GC, Stevenson JS, Kesler DJ, Garverick HA, Brown DR, Salfen BE. 2001. Inclusion of an intravaginal progesterone insert plus $\mathrm{GnRH}$ and prostaglandin F2 $\alpha$ for ovulation control in postpartum suckled beef cows. J Anim Sci, 79:2253-2259.

Lima F, Ribeiro ES, Bisinotto RS, Greco RF, Martinez N, Amstalden M, Thatcher WW, Santos JEP. 2013. Hormonal manipulations in the 5-day timed artificial insemination protocol to optimize estrous cycle synchrony and fertility in dairy heifers. J Dairy Sci, 96:7054-7065.

Macmillan KL, Thatcher WW. 1991. Effects of an agonist of gonadotropin-releasing hormone on ovarian follicles in cattle. Biol Reprod, 45:883-889.

Mapletoft RJ, Martinez MF, Colazo MG, Kastelic JP 2003. The use of controlled internal drug release devices for the regulation of bovine reproduction. $J$ Anim Sci, 81(E Suppl 2):E28-E36.

Mapletoft RJ. 2013. History and perspectives on bovine embryo transfer. Anim Reprod, 10:168-173.

Martinez MF, Adams GP, Bergfelt D, Kastelic JP, Mapletoft RJ. 1999. Effect of LH or GnRH on the dominant follicle of the first follicular wave in heifers. Anim Reprod Sci, 57:23-33.

Martinez MF, Kastelic JP, Adams GP, Cook RB,
Olson WO, Mapletoft RJ. 2002. The use of progestins in regimens for fixed-time artificial insemination in beef cattle. Theriogenology, 57:1049-59.

Martínez MF, Kastelic JP, Bó GA, Caccia M, Mapletoft RJ. 2005. Effects of oestradiol and some of its esters on gonadotrophin release and ovarian follicular dynamics in CIDR-treated beef cattle. Anim Reprod Sci, 86:37-52.

Martínez MF, Kastelic JP, Mapletoft RJ. 2007. Effects of estradiol on gonadotrophin release, estrus and ovulation in CIDR-treated beef cattle. Domest Anim Endo, 33:77-90.

Martins T, Talamoni JP, Sponchiado M, Maio JRG, Nogueira GP, Pugliesi G, Binelli M. 2017. Impact of estradiol cypionate prior to TAI and progesterone supplementation at initial diestrus on ovarian and fertility responses in beef cows. Theriogenology, 104:156-163.

Moreira F, de la Sota RL, Diaz T, Thatcher WW. 2000. Effect of day of the estrous cycle at the initiation of a timed artificial insemination protocol on reproductive responses in dairy heifers. J Anim Sci, 78:1568-1576.

Moreira F, Orlandi C, Risco CA, Schouten MJ, Lopes F, Thatcher WW. 2001. Effects of presynchronization and bovine somatotropin on pregnancy rates to a timed artificial insemination protocol in lactating dairy cows. $J$ Dairy Sci, 84:1646-1659.

Nasser L, Adams GP, Bó GA, Mapletoft RJ. 1993. Ovarian superstimulatory response relative to follicular wave emergence in heifers. Theriogenology, 40:713-724. Núñez-Olivera $R$, de Castro $T$, García-Pintos $C$, Bó GA, Piaggio J, Menchaca A. 2014. Ovulatory response and luteal function after eCG administration at the end of a progesterone and estradiol-based treatment in postpartum anestrous beef cattle. Anim Reprod Sci, 146:111-116.

Odde KG. 1990. A review of synchronization of estrus in postpartum cattle. J Anim Sci, 68:817-830.

Pereira MHC, Sanches CP, Guida TG, Rodrigues ADP, Aragon FL, Veras MB, Borges PT, Wiltbank MC, Vasconcelos JLM. 2013. Timing of prostaglandin $\mathrm{F}_{2 \alpha}$ treatment in an estrogen-based protocol for timed artificial insemination or timed embryo transfer in lactating dairy cows. J Dairy Sci, 96:2837-2846.

Perry George. 2017. 2016 statistics of embryo collection and transfer in domestic animals. Embryo Technology Newsletter, 35(4):8-23.

Peterson C, Alkar A, Smith S, Kerr S, Hall JB, Moore D, Kasimanickam, R. 2011. Effects of one versus two doses of prostaglandin F2alpha on AI pregnancy rates in a 5-day progesterone-based, COSynch protocol in crossbred beef heifers. Theriogenology, 75:1536-1542.

Ponsart C, Le Bourhis D, Knijn H, Fritz S, GuyaderJoly C, Otter T, Lacaze S, Charreaux F, Schibler L, Dupassieux D, Mullaart E. 2014. Reproductive technologies and genomic selection in dairy cattle. Reprod Fert Dev, 26:12-21.

Pursley JR, Mee MO, Wiltbank MC. 1995. Synchronization of ovulation in dairy cows using PGF $2 \alpha$ and GnRH. Theriogenology, 44:915-923. 
Rabaglino MB, Risco C, Thatcher MJ, Kim IH, Santos JE, Thatcher WW. 2010. Application of one injection of prostaglandin F2 $\alpha$ in the five-day Co-Synch + CIDR protocol for estrous synchronization and resynchronization of dairy heifers. J Dairy Sci, 93:10501058.

Revah I, Butler WR. 1996. Prolonged dominance of follicles and reduced viability of bovine oocytes. $J$ Reprod Fertil, 106:39-47.

Rico C, Fabre S, Medigue C, Clemente ND, Clement F, Bontoux M, Touze J-L, Dupont M, Briant E, Remy B, Beckers J-F, Monniaux D. 2009. AntiMullerian hormone is an endocrine marker of ovarian gonadotropin-responsive follicles and can help to predict superovulatory responses in the cow. Biol Reprod, 80:50-59.

Rodrigues CA, Teixeira AA, Ferreira RM, Ayres H, Mancilha RF, Souza AH, Baruselli PS. 2010. Effect of fixed-time embryo transfer on reproductive efficiency in high-producing repeat-breeder Holstein cows. Anim Reprod Sci, 118:110-117.

Sales JNS, Carvalho JBP, Crepaldi GA, Cipriano RS, Jacomini JO, Maio JRG, Souza JC, Nogueira GP, Baruselli PS. 2012. Effects of two estradiol esters (benzoate and cypionate) on the induction of synchronized ovulations in Bos indicus cows submitted to a timed artificial insemination protocol. Theriogenology, 78:510-516.

Sanches B V, Lunardelli PA, Tannura JH, Cardoso BL, Colombo Pereira MH, Gaitkoski D, Basso AC, Arnold DR, Seneda MM. 2016. A new direct transfer protocol for cryopreserved IVF embryos. Theriogenology, 85:1147-1151

Sartorelli ES, Carvalho LM, Bergfelt DR, Ginther OJ, Barros CM. 2005. Morphological characterization of follicle deviation in Nelore (Bos indicus) heifers and cows. Theriogenology, 63:2382-2394.

Sartori R, Fricke PM, Ferreira JCP, Ginther OJ, Wiltbank MC. 2001. Follicular deviation and acquisition of ovulatory capacity in bovine follicles. Biol Reprod, 65:1403-1409.

Sartori R, Haughian JM, Shaver RD, Rosa GJM, Wiltbank MC. 2004. Comparison of ovarian function and circulating steroids in estrous cycles of Holstein heifers and lactating cows. J Dairy Sci, 87:905-920.

Sartori R, Barros CM. 2011. Reproductive cycles in Bos indicus cattle. Anim Reprod Sci, 124:244-250.

Sartori R, Gimenes LU, Monteiro Jr PLJ, Melo LF, Baruselli PS, Bastos MR. 2016a. Metabolic and endocrine differences between Bos taurus and Bos indicus females that impact the interaction of nutrition with reproduction. Theriogenology, 86:32-40.

Sartori R, Prata1 AB, Figueiredo ACS, Sanches BV, Pontes GCS, Viana JHM, Pontes JH, Vasconcelos JLM, Pereira MHC, Dode MAN, Monteiro Jr PLJ, Baruselli PS. 2016b. Update and overview on assisted reproductive technologies (ARTs) in Brazil. Anim Reprod, 13:300-312.

Savio JD, Thatcher WW, Morris GR, Entwistle K, Drost M, Mattiacci MR. 1993. Effects of induction of low plasma progesterone concentrations with a progesterone-releasing intravaginal device on follicular turnover and fertility in cattle. $J$ Reprod Fertil, 98:77-84. Seguin B. 1987. Control of the reproductive cycle in dairy cattle. Proc Ann Mtg Soc Therio, pp. 300-308.

Seguin B. 1997. Strategies for estrus control to improve dairy reproductive performance. Proc Ann Mtg Soc Therio, pp.320-331

Selk GE, Fink MS, Peake CA. 1988. Estrus synchronization of cattle using eleven day or fourteen day prostaglandin protocols. Anim Sci Res Ag Expt Station, Oklahoma State Univ. MP, USA, 125:34-37.

Singh J, Dominguez M, Jaiswal R, Adams GP. 2004. A simple ultrasound test to predict superovulatory response in cattle. Theriogenology, 62:227-243.

Siqueira LGB, Dikmen S, Ortega MS, Hansen PJ. 2017. Postnatal phenotype of dairy cows is altered by in vitro embryo production using reverse $\mathrm{X}$-sorted semen. J Dairy Sci, 100:5899-5908.

Smith C. 1988. Applications of embryo transfer in animal breeding. Theriogenology, 29:203-212.

Souza AH, Carvalho PD, Rozner AE, Vieira LM, Hackbart KS, Bender RW, Dresch AR, Verstegen JP, Shaver RD, Wiltbank MC. 2014. Relationship between circulating anti-Müllerian hormone (AMH) and superovulatory response of high producing dairy cows. J Dairy Sci, 98:169-178.

Stevenson JS, Pursley JR, Garverick HA, Fricke PM, Kesler DJ, Ottobre JS, Wiltbank MC. 2006.Treatment of cycling and noncycling lactating dairy cows with progesterone during Ovsynch. J Dairy Sci, 89:2567-2578.

Stevenson JS. 2011. Alternative programs to presynchronize estrous cycles in dairy cattle before timed artificial insemination program. $J$ Dairy $S c i$, 94:205-217.

Surjus RS, Prata AB, Borsato M, Mattos FC, Martins da Silveira MC, Mourão GB, Pires AV, Wiltbank MC, Sartori R. 2014. In vivo embryo production in cows superovulated 1 or 2 days after ovum pick-up. Reprod Fertil Dev, 26:527-532.

Vasconcelos JLM, Silcox RW, Pursley JR, Wiltbank MC. 1999. Synchronization rate, size of the ovulatory follicle, and pregnancy rate after synchronization of ovulation beginning on different days of the estrous cycle in lactating dairy cows. Theriogenology, 52:1067-1078.

Viana João Henrique Moreira, Cristina Silva Figueiredo Ana, Siqueira Luiz Gustavo Bruno. 2017. Brazilian embryo industry in context: pitfalls, lessons, and expectations for the future. Anim Reprod, 14:476481

Washburn SP, Silvia WJ, Brown CH, McDaniel BT, McAllister AJ. 2002. Trends in reproductive performance in Southeastern Holstein and Jersey DHI herds. J Dairy Sci, 85:244-251.

Wiltbank JN, Zimmerman DR, Ingalls JE, Rowden WW. 1965. Use of progestational compounds alone or in combination with estrogen for synchronization of estrus. J Anim Sci, 24:990-994.

Wiltbank MC. 1997. How information of hormonal regulation of the ovary has improved understanding of timed breeding programs. In: Proc Ann Mtg Soc Therio, Montreal, QC, Canada. Montgomery, AL: Society for Theriogenology. pp. 83-97. 